\title{
The Importance of Transesophageal Echocardiography in Heart Harvesting for Cardiac Transplantation
}

\author{
Marcello Fonseca Salgado Filho ${ }^{1}$, Arthur Siciliano², Alexandre Siciliano ${ }^{3}$, Andrey José de Oliveira ${ }^{4}$, \\ Júlia Salgado ${ }^{5}$, Izabela Palitot 6
}

\begin{abstract}
Summary: Salgado Filho MF, Siciliano A, Siciliano A, Oliveira AJ, Salgado J, Palitot I - The Importance of Transesophageal Echocardiography in Heart Harvesting for Cardiac Transplantation.
\end{abstract}

Background and objectives: The use of transesophageal echocardiography (TEE) during heart harvesting for transplantation can guide the heart assessment, as harvesting a marginal heart can jeopardize the cardiac transplantation.

Case report: Male, 30 years old, suffered a car crash that resulted in a severe traumatic brain injury (TBI) that evolved to brain death. The patient was intubated and ventilated with a fraction of inspired oxygen of 0.6 , presetting Vt $500 \mathrm{~mL}, \mathrm{RR} 14 \mathrm{bpm}, \mathrm{PEEP}$ of $3 \mathrm{mmHg}, 99 \% \mathrm{O}_{2}$ saturation, and normal blood gases. He was also hypovolemic, with urine output of $9,300 \mathrm{~mL}^{\text {day }}{ }^{-1}$, sodium level of $157 \mathrm{mEq}^{\mathrm{L}} \mathrm{L}^{-1}$, hematocrit of $27 \%$, and BP $90 / 60 \mathrm{mmHg}$ maintained by infusion of norepinephrine $0.5 \mathrm{mcg} \cdot \mathrm{kg} \cdot \mathrm{min}^{-1}$. The patient was clinically optimized and evaluated by TEE, which showed normal size cardiac chambers, ejection fraction $66 \%$, anatomical and functional heart valves with no changes, and foramen ovale integrity. Immediately after the confirmation of cardiac viability and clinical stabilization, the patient was taken to the operating room and the harvest began. The ischemic period lasted two hours and the heart was successfully transplanted.

Conclusions: In most heart transplant services, the cardiac assessment is made subjectively by the surgeon who often does not have the anesthesiologist support to clinically optimize the donor. At the Instituto Nacional de Cardiologia (INC/MS), the anesthesiologist is part of the harvesting team in order to perform intraoperative TEE, evaluating objectively the harvested heart. In doing so, it provides greater chances of heart transplantation success with lower costs for the Brazilian public health system.

Keywords: Echocardiography, Transesophageal; Heart Diseases; Transplantation.

C2012 Elsevier Editora Ltda. All rights reserved.

\section{BACKGROUND AND OBJECTIVES}

Heart transplantation is an effective treatment for patients with end-stage heart failure, but the number of donors is much smaller than the number of patients who are on the waiting list for a transplant ${ }^{1}$. Between $10 \%-20 \%$ of patients die waiting for a heart transplant in the United Kingdom 2. In Brazil, despite the lack of epidemiological studies on the subject, DATASUS ${ }^{3}$ estimates that there are about 6.5 million patients with heart failure, and $1 / 3$ of these patients are hospitalized. Of the hospitalized patients, about 6,000 are admitted by the Brazilian Unified Health System (SUS from Portuguese).

Received from Instituto Nacional de Cardiologia/Ministério da Saúde (National Cardiology Institute/Health Ministry), Brazil.

1. Master in Health, Universidade Federal de Juiz de Fora (UFJF); Anesthesiologist at Instituto Nacional de Cardiologia/ Ministério da Saúde (INC/MS), Professor of Anesthesiology at UNIPAC-JF

2. MBA in Hospital Management; Chief of the Departamento de Anestesiologia of INC/MS 3. PhD in Cardiovascular Surgery; Head of the Department of Cardiovascular Surgery, INC/MS 4. Diploma in Cardiovascular Surgery; Head of the Pediatric Cardiovascular Surgery Division, INC/MS

5. Medical Student, Universidade Federal do Rio de Janeiro (UFRJ)

6. Registered nurse, Universidade Federal de Juiz de Fora (UFJF); Master in Health (UFJF); Professor of Nursing, Faculdade Estácio de Sá

Submitted on July 29, 2010.

Approved on June 19, 2011.

Correspondence to:

Dr. Marcello Fonseca Salgado Filho

Rua Alexandre Visentin, 100

Jardim do Sol

36061530 - Juiz de Fora, MG, Brazil

E-mail:mfonsecasalgado@hotmail.com
When a heart is evaluated for a possible transplant the terms remain controversial ${ }^{1}$. In an attempt to optimize donor heart, the invasive hemodynamic monitoring (arterial puncture, central venous and pulmonary artery catheters) has been used, in addition to the subjective visual analysis of a surgeon ${ }^{1}$. However, the non-harvesting of a heart may occur considering the patient's history that led to the brain stem death ${ }^{1}$.

Transthoracic echocardiography (TTE) has been used to assess the donor heart since $1988{ }^{4}$ and over the years it has gained increasing popularity for being a noninvasive, portable and rapid assessment of cardiac function, which also diagnoses the presence of related cardiac pathologies, such as patent foramen ovale or valvular disease ${ }^{3}$.

However, the use of transesophageal echocardiography (TEE) to evaluate the donor heart needs further scientific work ${ }^{1}$ because, as an adrenergic storm during the brain stem death ${ }^{5}$ and consequent cardiovascular overload occur, a transient myocardial ischemia may happen. Brain injury increases urine output, triggering sudden volume changes ${ }^{6}$ with hemodynamic repercussions. When these situations are associated with the TEE operator technical training, they can result in major constraints of the technique ${ }^{7}$.

In this case report, the aim is to demonstrate the importance of TEE in the evaluation of the donor heart for cardiac transplant due to the extreme importance of the harvesting time, and if a marginal heart is harvested ${ }^{3,8}$ the transplantation success will be jeopardized. 


\section{CASE REPORT}

Male, aged $30,70 \mathrm{~kg}, 1.75 \mathrm{~m}$, ASA physical status VI, suffered a car crash resulting in severe traumatic brain injury. Computed tomography showed cerebral intraparenchymal hemorrhage on the right with midline deviation, compression of the lateral ventricles and diffuse cerebral edema. The patient developed brain stem death, which was confirmed by the team of RIOTRANSPLANTE following the World Health Organization (WHO) guidelines ${ }^{9}$.

During the preanesthetic evaluation the patient was intubated, ventilated with the aid of a respirator (Servo $\left.{ }^{\circledR}\right)$, which parameters for fraction of inspired oxygen were 0.6 , tidal volume $500 \mathrm{~mL}$, respiratory rate $14 \mathrm{bpm}$, PEEP $3 \mathrm{mmHg}$, oxygen saturation of $99 \%$, and arterial blood gases within the normal range.

The patient had clinical signs of hypovolemia, with central venous pressure measuring $1 \mathrm{~mm} \mathrm{Hg}$, urine output was $9300 \mathrm{~mL}^{\text {day }}{ }^{-1}$, hematocrit $27 \%$, invasive blood pressure of $90 / 60 \mathrm{mmHg}$, and heart rate of $118 \mathrm{bpm}$. Noradrenaline was being administered at a dose of $0.5 \mathrm{mcg} . \mathrm{kg} \cdot \mathrm{min}^{-1}$.

After emptying the stomach with a nasogastric tube (\#18) and lubricating the oropharynx with lidocaine gel $2 \%$, the TEE probe (Vivid I, GE, Finland, Helsinki, 2007) was introduced into the esophagus and the examination was carried out with 20 cuts, as recommended by the American Society of Cardiovascular Anesthesia ${ }^{10}$. TEE evaluation showed normal size cardiac cavities (Figure 1), left ventricular ejection fraction of $66 \%$ by Simpson's technique ${ }^{11}$ (Figure 2), and anatomical heart valves without functional changes (Figure 3). The right ventricle was hypovolemic (Figure 4) and the heart showed a hyperkinetic profile, ratifying the picture of hypovolemia.

With the infusion of $1,500 \mathrm{~mL}$ of Ringer's solution \#3, guided by TEE to evaluate biventricular function, the heart rate decreased to $105 \mathrm{bpm}$, arterial pressure increased to $100 \times 70 \mathrm{mmHg}$, central venous pressure increased to $5 \mathrm{mmHg}$, and norepinephrine dose decreased to $0.3 \mathrm{mcg} \cdot \mathrm{kg} \cdot \mathrm{min}^{-1}$.

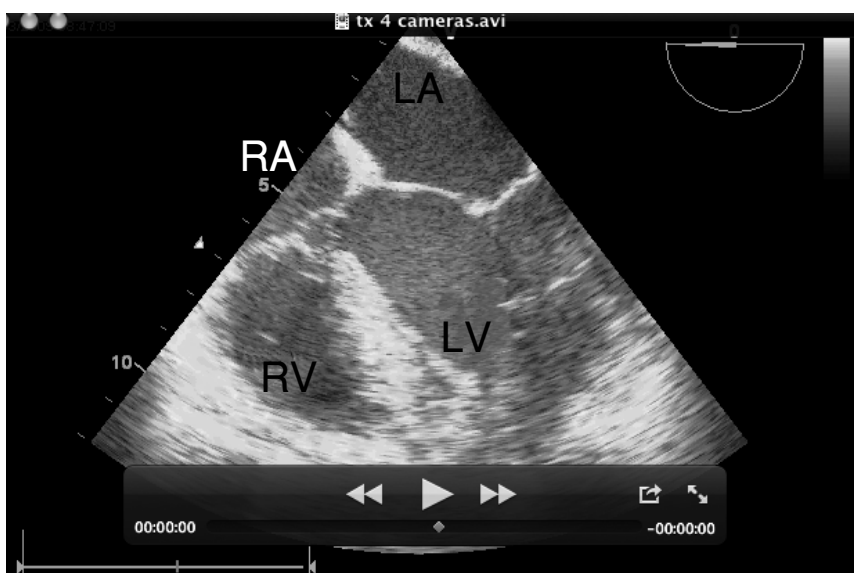

Figure 1 - Mid Esophageal Four Chamber View.

$\mathrm{RV}$ : right ventricle, RA: right atrium; LA: left atrium, LV: left ventricle.

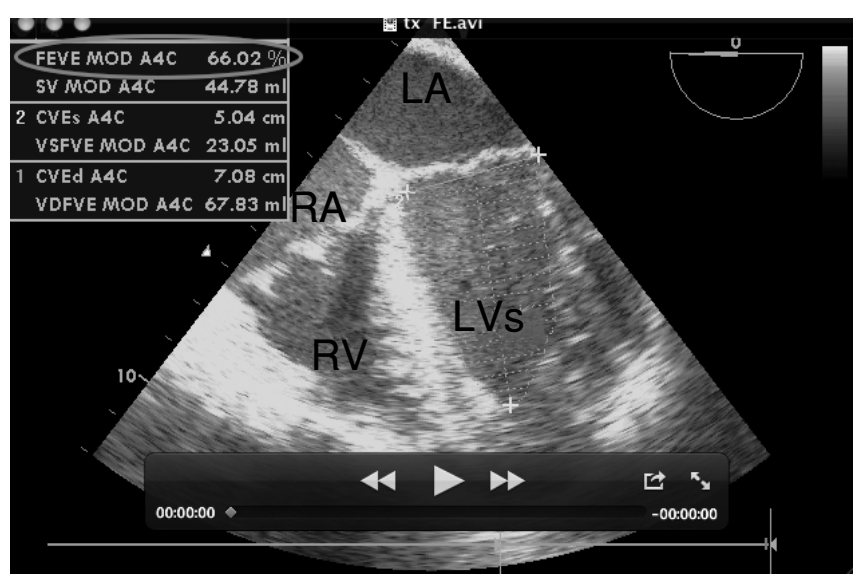

Figure 2 - Mid Esophageal Four Chamber View.

The Mark shows the left ventricular ejection fraction by Simpson's technique (shaded area). RV: right ventricle; RA: right atrium; LA: left atrium; LVs: left ventricle during systole.

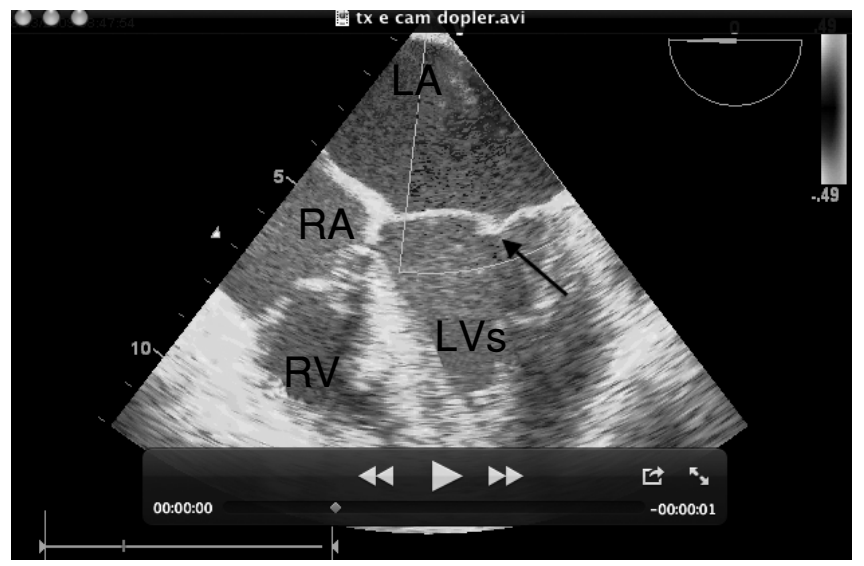

Figure 3 - Mid Esophageal Four Chamber View.

The Arrow shows the competent mitral valve during left ventricular systole on color Doppler. RV: right ventricle; RA: right atrium; LA: left atrium; LVs: left ventricle during systole.

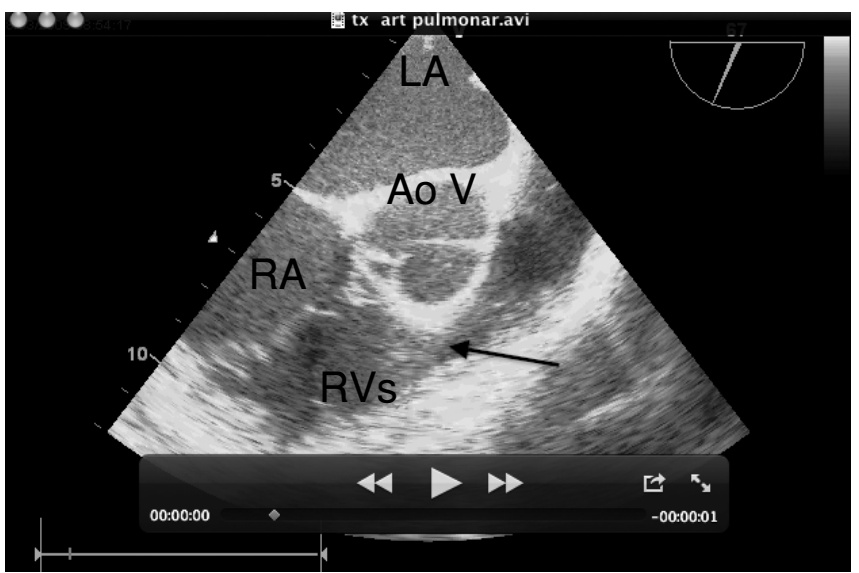

Figure 4 - Short Axis View of Aortic Valve and Inlet and Outlet Pathways of Right Ventricle through the Mid Esophagus.

The Arrow shows the right ventricle during systole virtually collapsed by hypovolemia. RVs: right ventricle during systole; RA: right atrium; LA: left atrium; PA: pulmonary artery; and Ao V: aortic valve. 
With the heart viability confirmed by TEE and by clinical stabilization, the patient was referred to the operating room and the harvesting was initiated. The period of cardiac ischemia lasted for two hours, and the heart was successfully transplanted into a patient with Chagas' cardiomyopathy, ASA IV, class 4 by New York Heart Association, and a left ventricular ejection fraction of $12 \%$. The patient was discharged 25 days after transplantation.

\section{DISCUSSION}

Although the first heart transplant was described by Barnard in 1967 , only in the 80s this surgical therapy gained worldwide popularity as an alternative technique for the treatment of terminal heart failure due to consistent advances in the management of the donor, to technical improvement of surgeons, to immunosuppressive drugs and to antibiotics ${ }^{1}$.

With the increase in life expectancy, the number of patients waiting for a heart transplant is increasing steadily and, unfortunately, many patients die waiting for a surgery ${ }^{2}$. Based on the public health situation, many heart transplant centers worldwide, according to studies such as Livi et al. ${ }^{13}$ and Kron et al. ${ }^{14}$, are no longer so strict while choosing a donor. Hosenpud et al. ${ }^{15}$ showed that (in 2000) $11.5 \%$ of the transplanted hearts were from donors over 50 years of age.

During the last two decades, cardiovascular outcomes resulting from brain stem death have been studied intensively worldwide ${ }^{2}$. Novitzky et al. ${ }^{16}$, in their experimental study with baboons, have found that after brain stem death a catecholaminergic storm occurs with subsequent depletion of these hormones - the Cushing reaction. Therefore there is a direct myocardial dysfunction ${ }^{6}$ and systemic inflammatory reaction ${ }^{5}$ that progresses to a cardiovascular collapse $5,6,16$. Over $25 \%$ of the organs not used for cardiac transplantation are due to circulatory instability or direct myocardial dysfunction ${ }^{12}$.

Some studies have shown that $67.5 \%$ of the donor hearts have some degree of segmental dysfunction in the heart walls and $36 \%$ have global dysfunction of the left ventricular segmental function diagnosed by echocardiography during heart harvesting ${ }^{14,17}$. However, these abnormal hearts, once transplanted, showed improvement in cardiac function immediately after transplantation, with continued development up to 15 months after transplantation ${ }^{14,17}$.
The Brazilian Unified Health System (SUS from Portuguese), faced with the national reality of the public health costs, recommends not harvesting marginal hearts ${ }^{3,18}$ due to the high surgical and post-operative costs. Therefore, the hearts of donors over 50 years old; with cardiac malformation on echocardiography; left ventricular dysfunction on echocardiography, significant coronary disease (for patients over 45 years of age a coronary angiography is mandatory); septicemia; high doses or long-term use of vasoactive drugs (even after correction of hypovolemia); or HIV, hepatitis B and/or C infection detected by serology are all excluded ${ }^{3,18}$.

In addition to myocardial dysfunction, diabetes insipidus is one of the metabolic changes found in brain death, which are characterized by polyuria, low urine osmolality, high serum osmolality, and hypernatremia ${ }^{19}$. This physiological status associated with decreased catecholamine levels and myocardial dysfunction triggers severe hemodynamic instability, which makes the clinical management of these patients a great challenge to the anesthesiologist.

In this report, the patient had clinical (urine output of $5.5 \mathrm{~mL} . \mathrm{kg} . \mathrm{h}^{-1}$, low central venous pressure, hypotension, and tachycardia) and laboratory (sodium 157 meq.dL-1, serum osmolality of approximately 314 mOsmo. $\mathrm{kg}^{-1}$ ) signs of diabetes insipidus. In addition, noradrenaline was being continuously administered. TEE examination was important because it showed good myocardial function (EF 60\%), with no anatomical and/or functional changes of the heart valves, and guided the volume optimization with crystalloid solution.

After the hemodynamic profile satisfactory response, with fluid replacement, improvement of clinical conditions, and decreased norepinephrine, the patient was referred to the operating room to have the heart harvested.

\section{CONCLUSION}

In most heart transplant services, the cardiac assessment is made subjectively by the surgeon who does not often have the anesthesiologist support to clinically optimize the donor. At the INC/MS, the anesthesiologist is part of the harvesting team in order to perform intraoperative TEE, objectively evaluating the harvested heart. There is then a greater chance of heart transplantation success at lower costs to the Brazilian public health system. 


\section{REFERÊNCIAS/REFERENCES}

1. Venkateswaran RV, Bonser RS, Steeds RP - The echocardiographic assessment of donor heart function prior to cardiac transplantation. Eur J Echocardiography, 2005;6:260-263.

2. Anyanwu AC, Rogers CA, Murday AJ - Intrathoracic organ transplantation in the United Kingdom 1995-99: results from the UK cardiothoracic transplant audit. Heart, 2002;87:449-454.

3. Ministério da Saúde. Governo Federal. DATASUS. Disponível em: www.datasus.gov.br.

4. Gilbert EM, Krueger SK, Murray JL et al. - Echocardiographic evaluation of potential cardiac transplant donors. J Thorac Cardiovasc Surg, 1988;95:1003-1007.

5. Powner DJ, Hendrich A, Nyhuis A, Strate R - Changes in serum catecholamine levels in patients who are brain dead. J Heart Lung Transplant, 1992;11:1046-1053.

6. Rona G. Catecholamine cardiotoxicity. J Mol Cell Cardiol, 1985;17:291306.

7. Lewandowski TJ, Aaronson KD, Pietroski RE, Pagani FD et al. Discordance in interpretation of potential donor echos. J Heart Lung Transplant, 1998; 17(Suppl.1):S100.

8. English TA, Spratt $P$, Wallwork $J$ et al. - Selection and procurement of hearts for transplantation. Br Med J,1984;288:1889-1891.

9. Wijdichs EFM - The diagnosis of brain desth. N Engl J Med, 2001;344:1215-1221.

10. Shanewise JS, Cheung AT, Aranson S et al. - ASE/SCA guidelines for performing a comprehensive intraoperative multiplane transesophageal echocardiography examination: recommendations of the American Society of Echocardiography Council for Intraoperative echocardiography and he Society of Cardiovascular Anesthesiologist Task Force for certification in perioperative transesophageal Ecocardiography. AnesthAnalg, 1999;89:870-884.

11. Urbanowicz JH, Shaaban MJ, Cohen $\mathrm{NH}$ et al. - Comparison of transesophageal echocardiographic and scintigraphic estimates of left ventricular end-diastolic volume index and ejection fraction in patients following coronary artery bypass grafting. Anesth, 1990;72:607612.

12. Szabo G - Physiologic changes after brain death. J Heart Lung Transplant, 2004;23:223-226.

13. Livi U, Bortolutti U, Luciani Gb et al. - Donor shortage in heart transplantation. Is extension of donor ages limitsjustified? J Thorac Cardiovasc Surgery, 1994;107:1346-55.

14. Kron IL, Tribble CG, Kern JA et al. - Successful transplantation of marginally acceptable thoracic organs. Ann Surg, 1993; 217: 518524.
15. Hosenpud JD, Bennet LE, Keck BM et al. - The registry of the international society for heart and lung transplantation: the official report - 2001. J Heart Lung Transplant, 2001;20:805-15.

16. Novitzky D, Wicomb WN, Cooper DKC et al. - Electrocardiographic, haemodynamic, and endocrine changes occurring during experimental brain death in the Chacma baboon. Heart Transplant, 1984;4:63-69.

17. Seiler C, Laske A, Galino A et al. - Echografic evalution of left ventricular wall motion before and after transplantation. J Heart Lung Transplant, 1992;11:867-874.

18. Associação Brasileira de Transplantes de Órgãos - Disponível em http://www.abto.org.br.

19. Berry $\mathrm{R}-$ Brainstem death and the management of the organ donor. Anaesth Intensive Care, 2006;7:212-214. 